\title{
Gesetzmäßigkeiten der Bodenentwicklung im Quartär
}

\author{
Von Libuše Smolíková, Prag \\ Mit 6 Abbildungen und 2 Tabellen
}

Zus a m m e n f a s s u n g. Der Übersichtsaufsatz soll den gegenwärtigen Stand der Quartärpedologie in Mitteleuropa besprechen, auf die Voraussetzungen, die zu erfüllen sind, aufmerksam machen sowie die Möglichkeiten erörtern, die der Paläopedologie im Rahmen der Quartärforschung zur Verfügung stehen.

Im methodischen Teil werden die Ergebnisse der klassischen analytischen Bodenkunde und der Bodenmikromorphologie einander vergleichend gegenüberstellt und die Bedeutung der mikromorphologischen Methoden für die Paläopedologie hervorgehoben. Erst aus der engsten Verknüpfung eines vollentfalteten naturwissenschaftlichen Bodensystems mit der Mikromorphologie sowie Sedimentologie ergibt sich eine Vollausnützung der Bodenbildungen für die Zwecke der Quartärforschung.

Im Kapitel über die Stellung der Böden im quartären klimabedingten Sedimentationszyklus werden die einzelnen Hauptphasen der Bodenbildung erörtert, von denen auch die allgemeinen Gesetzmäßigkeiten abgeleitet werden können.

Die Entstehungsdynamik bestimmter Formen der Bodenerhaltung, die Charakteristik von ruhigen und gestörten Lagen sowie weitere verwandte Erscheinungen werden im Kapitel über das Verhältnis der Bodenbildung zur Abtragung und Sedimentation besprochen. Im folgenden Abschnitt, der den paläopedologischen Provinzen gewidmet ist, werden die Probleme der horizontalen und vertikalen Zonengliederung und die Bodenbildungsfazies sowie die Fragen des heutigen Standes der Bodenbildung und die substratbedingten Fazies erörtert. Aus der Tatsache, daß die Böden weit verbreitete Zeugen bestimmter Standortverhältnisse darstellen, geht schließlich ihre hohe landschafts- und klimageschichtliche Bedeutung hervor.

Aus der vorliegenden Ubersicht ist ersichtlich, welche bedeutsame Rolle den Bören bei der Erforschung der jüngsten geologischen Vergangenheit zukommt. Unter Voraussetzung, daß die erörterten Richtlinien eingehalten und die paläopedologischen Ergebnisse mit denjenigen anderer Quartärdisziplinen kritisch verglichen werden, wird die Paläopedologie nicht nur zu einer der Hauptmethoden der Quartärforschung, sondern wird auch selbst feste naturwissenschaftliche Grundlagen gewinnen, die ihr oft noch fehlen.

$\mathrm{Summary}$. The object of the paper is to describe the present-day level of Quaternary pedology in Central Europe, to focuse attention to the disciplines that have to be followed, and to evaluate the possibilities of the paleopedology during the investigation of the Quaternary.

The methodical part offers a brief critical comparison of classical pedology with soil micromorphology and underlines the importance of a micromorphological method for fossil soils. It is only through the joint study of fully developed system of soils based on a broad knowledge of natural science, with soil micromorphology and sedimentology, that the soils can be used in the Quaternary research.

In the chapter dealing with the position of soils in the Quaternary climatic-sedimentary cycle, individual phases of the main soil formation are described and principal laws issuing from them are cited.

The principles of the origin of various forms of soil conservation, the discernment of quiet and disturbed positions etc. are the prime subject of the chapter devoted to the relation of soils to erosion and accumulation. The problems of vertical and horizontal zoning, of the facies of soil development - an analog of the present-day state, and of the facies conditioned by the substratum, are treated in the chapter on paleopedological provinces.

The paleogeographical, paleoclimatic and stratigraphic importance of the soils is well evident from the fact that they are the most widely distributed witnesses of certain site conditions.

The outline given reveals a far-reaching importance of soils for the knowledge of the youngest geological past. If the phenomena quoted are studied, and the results obtained are correlated with the knowledge obtained in other scientific branches, the pedology will become one the principal investigation methods of the Quaternary and will acquire the frequently lacking broad base of natural sciences. 


\section{Einleitung}

Vom Gesichtspunkt der Quartärforschung aus sind die Bodenbildungen von außerordentlicher Bedeutung. Sie stellen nicht nur deutliche stratigraphische Trennhorizonte, sondern auch Standortsanzeiger dar, die bestimmte Klimaverhältnisse kennzeichnen. Demgemäß kommt der Pedologie bzw. der Paläopedologie eine bedeutsame Rolle in der Quartärgeologie zu.

Die Ausnutzung der bodenkundlichen Ergebnisse für quartärgeologische Zwecke ist recht vielseitig mannigfaltig, konnte allerdings bisher nicht voll zur Geltung kommen, da die theoretischen Grundlagen bis in die letzte Zeit hinein unzureichend blieben. Mit den Bodenbildungen befassen sich viele Quartärforscher, die oft über keine tieferen pedologischen Kenntnisse verfügen, was oft falsche und zuweilen widersprüchliche Ausdeutungen zur Folge hat, die ein Erkennen von Gesetzmäßigkeiten der Bodenbildungsvorgänge im Quartär sehr erschweren.

Um solche Fehlvorstellungen zu beseitigen, muß man bei der paläopedologischen Untersuchung folgende Kriterien berücksichtigen:

1. Ein vollständig bearbeitetes System von rezenten Böden (KuBiëNa 1953, MückeNHAUSEN 1962), das sämtliche Bodenbildungen in allen Entwicklungsstufen umfaßt und eine Feingliederung ermöglicht, die die in der land- und forstwirtschaftlichen bodenkundlichen Praxis angewendeten Systeme meist nicht bieten können.

2. Beachtung der gegenseitigen Beziehungen zwischen der Bodenbildung und dem geologischen Geschehen.

3. Stellung der Böden im Rahmen der gesamten Geobiozönose.

4. Anwendung derartiger Methodik, die imstande ist, solche Merkmale zu erfassen, auf die sich die Quartärbodenkunde stützen kann.

Aus den angeführten Punkten ergibt sich, daß paläopedologische Untersuchungen in vielen Fällen auf außerordentlich komplizierte Probleme stoßen. Es ist daher kein Wunder, daß vor allem in älteren Schriften recht einseitige Gesichtspunkte zu finden sind; die Beschreibungen der Böden werden oft sehr vereinfacht; zuweilen sind es nur volkstümliche Bezeichnungen, z. B. Tabakzonen, Laimenzonen, limon fendillé usw. (vgl. Lautridou 1969); wesentliche Merkmale finden dabei oft kaum Beachtung (z. B. verschiedene Typen der braungefärbten Böden werden nicht unterschieden), während andere überschätzt werden (z. B. die auffallend dunkle Farbe der Tschernoseme). In anderen Fällen kommt es zu Verwechslungen sekundärer Bodenderivate mit autochthonen Böden usw. Aus diesen Gründen ist es kaum möglich, die Beschreibungen in vielen älteren Schriften kritisch auszuwerten.

Mein Aufsatz hat sich deshalb zum Ziel gesetzt, den gegenwärtigen Stand der Quartärbodenforschung in Mitteleuropa zu besprechen, auf die notwendigen Voraussetzungen aufmerksam zu machen und die Möglichkeiten zu würdigen, die der Paläopedologie heute zur Verfügung stehen.

\section{Methodische Voraussetzungen}

Eine Bodenuntersuchung ist nicht isoliert durchzuführen, da sie in den Rahmen der quartärgeologischen Untersuchungen gehört.

Die Geländeuntersuchung. Bei jeder Bodenbildung sind ihre Lagerungsverhältnisse und Ausbildung im Bereiche des gesamten Aufschlusses sowie ihre Beziehungen zum Relief zu beachten. Nur auf diese Weise kann man z. B. die sekundären Umprägungen und Störungen erkennen sowie die Abschnitte begrenzen, in denen Bodenderivate akkumuliert sind. Aus der Durchverfolgung der Bodenhorizonte ergibt sich auch eine 
richtige Auswertung vom Standpunkt der Polygenese aus; man kann z. B. das Verhältnis der reliefbedingten Bodenkomplexe und der entsprechenden polygenetischen Bodenbildungen erkennen. Außerdem müssen die stratigraphischen Beziehungen der Böden und deren Derivate, d.h. die Aufeinanderfolge der Böden und Bodensedimente sowie die Bildung von gesetzmäßig aufgebauten Bodenkomplexen berücksichtigt werden. Schließlich soll der eventuelle Fossilgehalt der Böden und die Formen der biologischen Perstruktion (Wühlund Wurmgänge, Wurzelbahnen usw.) aufgenommen werden.

Die Laboruntersuchungen. Die Probenentnahme wird auf die Ergebnisse der vorangehenden Profiluntersuchung gestützt. Soll eine Laboruntersuchung von Erfolg gekrönt sein, so muß sie das Totalbild des Bodens sowie die Spuren einer maximalen Zahl von Bodenbildungsvorgängen erfassen, die den Boden in verschiedenen, $d$. h. auch längst vergangenen Entwicklungsphasen beeinflußt haben. Die älteren üblichen Methoden der physikalischen und chemischen Bodenuntersuchung stellten sich in dieser Hinsicht als allzu analytisch heraus. Die Ergebnisse, die sich nur auf einzelne, oft sehr spezielle Merkmale beziehen, sowie eine Synthese, die sich auf solche Einzelmerkmale stützt, sind von geringerem Wert, als eine Untersuchung, die das Gesamtbild der Bodenentwicklung erfaßt und die einzelnen Stufen der Bodenbildung in voller Variationsbreite sowie in Beziehung zu den Standortsbedingungen erkennen läßt. Bestimmte Bodenformen sollen erfaßt werden, auch wenn sie nur in Resten vorhanden und mit Fragmenten anderer Bodenbildungen vermengt sind. Die Auswahl der analytischen Methoden muß dabei dem Charakter der einzelnen untersuchten Objekte entsprechen. Unentbehrlich bleibt jedenfalls die Bodenmikromorphologie, da nur sie imstande ist, das Gesamtbild des Bodens zu erfassen.

Ferner sei beachtet, daß eine vollständige Abfolge fossiler Bodenbildungen in den quartären Sedimentkomplexen praktisch nirgends erhalten ist. Eine gewisse Ausnahme stellen lediglich die Lößserien der Trockengebiete dar, die nicht nur das vollkommenste Bild der zyklischen Entwicklung bieten, sondern auch annähernd die gesamte Zeitfolge erfassen können. Der Löß ist hierbei als ideales Ausgangsmaterial zu betrachten, da er auf großen Flächen und in verschiedenen Zeitabschnitten eine sehr einheitliche Ausbildung aufweist, abgesehen davon, daß er als Sedimentdecke die alten Bodenbildưngen ausgezeichnet konservieren kann. Alb Substrat reagiert der Löß sehr empfindlich auf alle Veränderungen des Klimas und der Vegetation, so daß er selbst die geringsten Schwankungen in Form von schwach ausgebildeten Böden erkennen läßt (KuBiëNA 1956a).

So bietet die Untersuchung von fossilen Böden innerhalb der Lößserien folgende Vorteile:

1. Möglichkeit eines Vergleichs von verschiedenen Böden aus einem relativ einheitlichen Substrat.

2. Die Böden sind in ganzen Komplexen vorhanden, so daß verschiedene Bodentypen und -varitäten an einem Punkt untersucht werden können.

\section{Position der Böden im Rahmen der klimabedingten Sedimentationszyklen des Quartärs}

Die Quartärablagerungen, Böden und Abtragungsniveaus bilden gesetzmäßige Aufeinanderfolgen, die sich nach den periodischen Klimaschwankungen zyklisch wiederholen. Dieser Wandel, auf den sich die meisten Systeme der Quartärstratigraphie mehr oder weniger stützen, wird als klimabedingter Sedimentationszyklus bezeichnet. Den Böden kommt dabei eine bedeutende Rolle zu, und zwar sowohl was die stratigraphischen als auch die standortsgeschichtlichen Aspekte anbelangt, da auf Grund der Bodenbildungen die Umweltbedingungen in bestimmten Zeitabschnitten rekonstruiert werden können (Bronger 1966, 1969, Fedoroff 1969). Im einzelnen können die Verhältnisse recht kom- 
pliziert sein, was darauf zurückgeht, daß die Zyklen I. Ranges noch in Teilzyklen II. Ranges zerfallen, deren Phasen weniger ausgeprägt sind (vgl. KukLA 1961a).

Das vollständige Bild der zyklischen Entwicklung bieten die Lößserien der Trockenlandschaften Mitteleuropas, in denen fast die gesamte Zeitfolge durch Sedimente und Bodenbildungen vertreten ist. Im Vergleich dazu sind die übrigen Sedimentserien nur fragmentarisch entwickelt, was sowohl ihre flächenmäßige Verbreitung als auch die Vertretung der einzelnen Zeitabschnitte betrifft (vgl. z. B. die Binnenwasserkalke, Flußterrassen oder Höhlenausfüllungen). Aus der beigefügten Übersichtstabelle, die den Sedimentations- und Bodenbildungszyklus der Lößserien im Raume der mitteleuropäischen Trockenlandschaften darstellt, ist ersichtlich, daß vom paläopedologischen Gesichtspunkt aus den Phasen 2 und 3 die Hauptrolle zukommt (Kukla 1961a, Zagwijn \& Paepe 1969). Sie sind, wie auch die übrigen Phasen kürzlich in einem anderen Zusammenhang näher dargestellt (SMOLíkovÁ 1972, im Druck); der notwendigen Kürze wegen muß auf diese Publikation verwiesen werden. Die Tabelle 1 vermag nur einen sehr gerafften Überblick über die komplizierten Sedimentations- und bodenbildenden Vorgänge zu vermitteln.

Tabelle 1

Sedimentations-und Bodenbildungszyklus der Lößserien

\begin{tabular}{|c|c|c|c|}
\hline \multicolumn{2}{|c|}{ Phase } & Sedimentation & \multirow{2}{*}{$\begin{array}{l}\text { Bodenbildung } \\
\begin{array}{l}\text { Löß-Rohboden - Verlössung } \\
\text { (oblëssovanie, loessification) }\end{array}\end{array}$} \\
\hline & 6 & $\begin{array}{l}\text { Lößbildung }- \text { andere Sedimentations- } \\
\text { bzw. Bodenbildungsvorgänge sehr be- } \\
\text { schränkt }\end{array}$ & \\
\hline & 5 & $\begin{array}{l}\text { Abspülungssedimentation, die rhythmisch } \\
\text { in die allmählich zunehmende äolische } \\
\text { (Löß-) Sedimentation übergeht und zu- } \\
\text { weilen durch Solifluktion unterbrochen } \\
\text { wird } \\
\text { (Lehmbröckelsande) } \\
\text { Intensive Akkumulation humoser } \\
\text { Bodensedimente }\end{array}$ & $\begin{array}{l}\text { Allmählicher Ubergang zum Löß; in kür- } \\
\text { zeren Ruhepausen Entstehung von } \\
\text { schwach ausgebildeten Böden der Tscher- } \\
\text { nosemreihe }\end{array}$ \\
\hline 胥 & 4 & $\begin{array}{l}\text { Kurzfristige äolische Sedimentation } \\
\text { ("Marker") }\end{array}$ & $\begin{array}{l}\text { Unterbrechung der Bodenbildung; } \\
\text { Ausklingen der Wurmtätigkeit }\end{array}$ \\
\hline 空 & 3 & $\begin{array}{l}\text { Mäßige Sedimentation (vor allem Hang- } \\
\text { ablagerungen, nur selten etwas Löß) - } \\
\text { mehrfacher Phasenwandel von ruhigen } \\
\text { Abschnitten und stärkerer Hangsedimen- } \\
\text { tation }\end{array}$ & $\begin{array}{l}\text { Tschernoseme unter Grassteppe (trocke- } \\
\text { nes und relativ kühles Binnenklima); } \\
\text { periodische Verlössung in kalten Zwi- } \\
\text { schenphasen }\end{array}$ \\
\hline & 2 & $\begin{array}{l}\text { Sedimentations- und Abtragungsruhe - } \\
\text { intensive Verwitterung }\end{array}$ & $\begin{array}{l}\text { Braune Bodenbildungen von Parabraun- } \\
\text { erde-Typus; Gipfel- und Spätphase der } \\
\text { Interglaziale - dichte Vegetationsdecke } \\
\text { - geschlossene Wälder }\end{array}$ \\
\hline & $==-=$ & 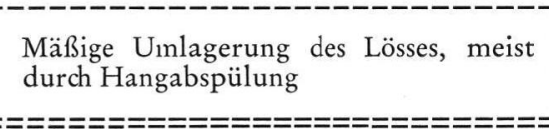 & 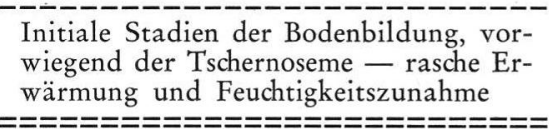 \\
\hline & $===$ & 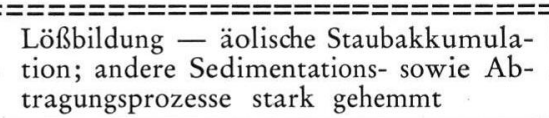 & 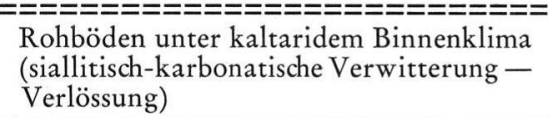 \\
\hline
\end{tabular}

Es soll nur nochmals darauf hingewiesen werden, daß praktisch alle fossilen Böden der Lößserien deutliche Merkmale der Polyge nese aufweisen, die bei den Interglazialböden am stärksten zum Vorschein kommen (s. Abb. 1) und mit dem Ablauf des klimati- 
schen Zyklus gesetzmäßig zusammenhängen können. Bei den meisten Bodenbildungen kann man folgende sukzessive Entwicklungsstadien unterscheiden:

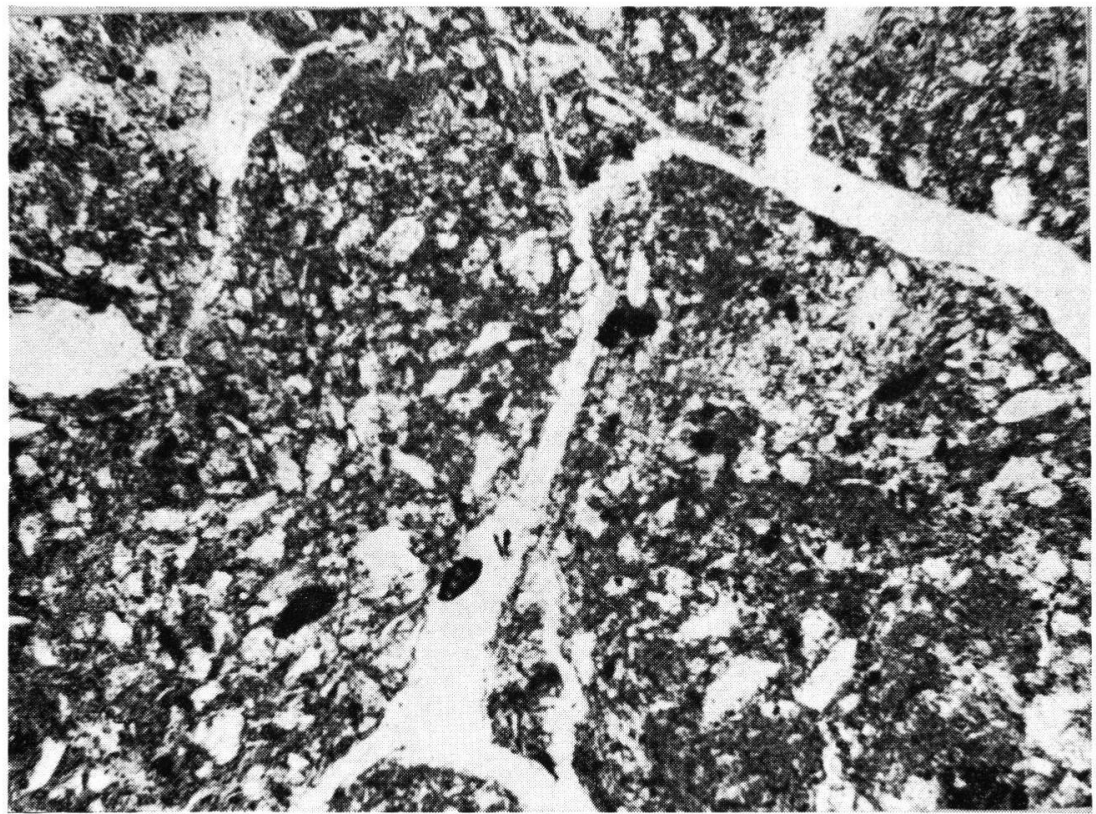

Abb. 1. Pseudotschernosem aus einer Parabraunerde, deren Substrat von ausgesprochenem Braunlehm-Charakter ist. - Unterer polygenetischer Boden von PK VII („Waal“-Interglazial), Červeny kopec bei Brünn. Vergr. ca. 80-fach.

1. Lößrohboden $\rightarrow$ Initialstadien, denen Pararendsinen bzw. „arktischen“ Braunerden entsprechen

2. Entkalkung und Freilegung des Braunlehmteilplasmas (Parabraunerde bis Braunlehm unter Wald im feuchtwaren Klima der Hochinterglaziale)

3. Granulierung bis Vererdung (Austrocknung und mäßige Temperaturminderung)

4. Mäßige Pseudovergleyung (ausklingende Warmzeiten)

5. Neue Sedimentation und Bildung von humosen Böden der Tschernosemreihe (zunehmende Kontinentalität zu Beginn der Kaltzeit)

6. Schwache Pseudovergleyung, die auf kurzfristige feuchte Schwankung zurückzuführen ist

7. Mechanische Störungen und sekundäre Kalkanreicherung infolge einer neuen Verlössungsphase (hochkaltzeitliches Klima).

Die Abfolge dieser nur mikromorphologisch erfaßbaren Vorgänge präzisiert wesentlich die bisherigen Kenntnisse über den Verlauf des klimatischen Zyklus und stellt eine seiner grundsätzlichen Gesetzmäßigkeiten dar (SMOLíkovÁ 1968a).

\section{Verhältnis der Böden zu den Abtragungsvorgängen}

Vom paläopedologischen Gesichtspunkt aus ist für das Verhältnis der Bodenbildung zur Abtragung bzw. Sedimentation das Relief maßgebend. Aus der Tatsache, daß das Relief einen der fünf Hauptfaktoren der Bodenbildung darstellt und daß seine Verände- 
rungen auf den quartären klimabedingten Sedimentationszyklus zurückgehen, ergibt sich auch die absolute Abhängigkeit der Bodenbildung von der Geländemorphologie.

Man kann zwei Hauptfälle unterscheiden:

1. Ruhige Lagen

2. Lagen, die durch a) Abtragung

b) Sedimentation beeinflußt werden.

1. In $\mathrm{r}$ uhigen L a gen vollzieht sich die Bodenbildung ungestört und kann das $\mathrm{K}$ limax st ad i u m erreichen.

2. Lagen, die dem Abtrag ausgesetzt sind, weisen entweder schwach ausgebildete Böden (z. B. an steileren Hängen) oder Bodenreste auf, bei denen einer oder mehrere Horizonte abgetragen wurden.

Böden, deren Bildung durch Sedimentation gehemmt wurde, sind an die Sedimentationsräume, d. h. an verschiedene Senken, Dellen oder Hangfußlagen gebunden.

Innerhalb eines jeden klimabedingten Zyklus erfolgt ein gesetzmäßiger Lagenwandel, der sich rhythmisch wiederholt:

1. Die Warmzeiten sind stets durch eine wesentliche Ausbreitung der ruhigen L a gen gekennzeichnet.

2. Die Kaltzeiten weisen die maximale Ausdehnungdergestörten L a g e $n$ aus.

Diese Veränderungen sind für die Zeiten der ungestörten Bodenbildung maßgebend. Nur wenige bleiben dauerhaft in Ruhe, was die Erhaltung von alten Reliktböden ermöglicht, die stets stark polygenetische Merkmale aufweisen. Auf den übrigen Flächen, d.h. im größten Teil des mitteleuropäischen Raumes, kann eine Abstufung der Bodenbildung verfolgt werden, die der Reliefentwicklung entspricht. Diese geht wieder auf die Bewegungen der Erosionsbasis, die erosive Tätigkeit des Wassers sowie auf die Flächenabtragung zurück. Die Einzelstadien dieser Entwicklung kommen am besten im Bereich der Flußterrassen zum Ausdruck, von denen im betreffenden Flußgebiet auch die Skala der zeitlichen Einordnungsmöglichkeiten abgeleitet werden kann. Als Beispiel sei Innerböhmen angeführt, wo folgende Gebiete zu unterscheiden sind:

a) Gebiet mit \pm konserviertem tertiärem Relief — im wesentlichen die Geländestufe über der höchsten Pleistozänterrasse (Lysolajer Gruppe im Prager Raum, etwa $100 \mathrm{~m}$ über dem gegenwärtigen Fluß).

b) Gebiet der qartären Abtragung-d.h. im Niveau der höchsten Pleistozänterrasse und tiefer. Hier besteht die Möglichkeit einer weiteren Abstufung, d. h. einer Unterscheidung des alt-, mittel- und jungpleistozänen Reliefs. Stellenweise kann noch eine eingehendere Einteilung durchgeführt werden, die von der Zahl der unterscheidbaren Terrassenstufen abhängt. Entsprechend können auch andere Typen der Modellation, z. B. das glaziäre, äolische oder Solifluktionsrelief, je nach den Bedingungen im untersuchten Gebiet benützt werden (PICARD 1960).

Im Rahmen der einzelnen Landschaften bilden die Bodentypen gesetzmäßige reliefbedingte Abfolgen, die als Catena bezeichnet werden. Die alten Böden sind nur an bestimmte Glieder dieser Bodenbildungsketten gebunden. Als Beispiel seien die durch Täler aufgegliederten Fastebenen angeführt: die Talhänge und -sohlen werden durch wiederholte Abtragung und Erosion betroffen, so daß in diesen Reliefabschnitten eine Erhaltung von autochthonen alten Bodenbildungen kaum möglich ist. Hingegen sind die alten Böden auf ebenen Abschnitten der Plateaus in verschiedenem Maße vertreten. Beste Beispiele einer 
wiederholten und zeitlich abgestuften Bodenentwicklung bieten große Aufschlüsse in den Lößserien mit „teleskopischer" Superposition im Hangenden von Flußterrassentreppen (J. KuKLA 1961 b).

Auch nach dem Auftreten von Kalksteinböden (Rendsinen- und Terrae-calcis-Gruppe) kann auf das minimale Alter des betreffenden Abschnittes der Geländeoberfläche geschlossen werden, wodurch auch die Abtragungsvorgänge altersmäßig erfaßt werden, auf die das untersuchte Relief zurückgeht. Derartigen Bodenresten kommt bei der stratigraphischen Einordnung von Terrassen, Travertinen, Hangschuttbrekzien und anderen Quartärbildungen bzw. Abtragungsvorgängen eine hervorragende Rolle zu, namentlich dort, wo andere stratigraphische Kriterien nicht zur Verfügung stehen.

Auf Grund der Entwicklungsstufe und des Erhaltungstypus von Terrae calcis und Rendsinen kann auch das Alter der betreffenden Karstoberflächen abgeschätzt werden, etwa nach dem folgenden Schema:

1. Relikte Terra-rossa-Böden weisen immer auf tertiäre oder ältestqu a r tär e Karstformen hin, die durch späteren Abtrag nicht zerstört wurden.

2. Relikte Terra-f usca-Böden kommen ledgilch auf ebenen Flächen vor, die während des Ple istozäns entstanden (allerdings nur dort, wo jüngere Abtragungsvorgänge nicht mehr zur Geltung kamen).

3. Oberflächen ohne Terrae calcis, die nur verschiedene Entwicklungsstufen von $\mathrm{R}$ e n d s in e n (Abb. 2) tragen, sind jung bzw. durch jungpleistozänen Abtrag betroffen (SMOLíková 1961, 1963, SMOLíková \& LožEK 1962).

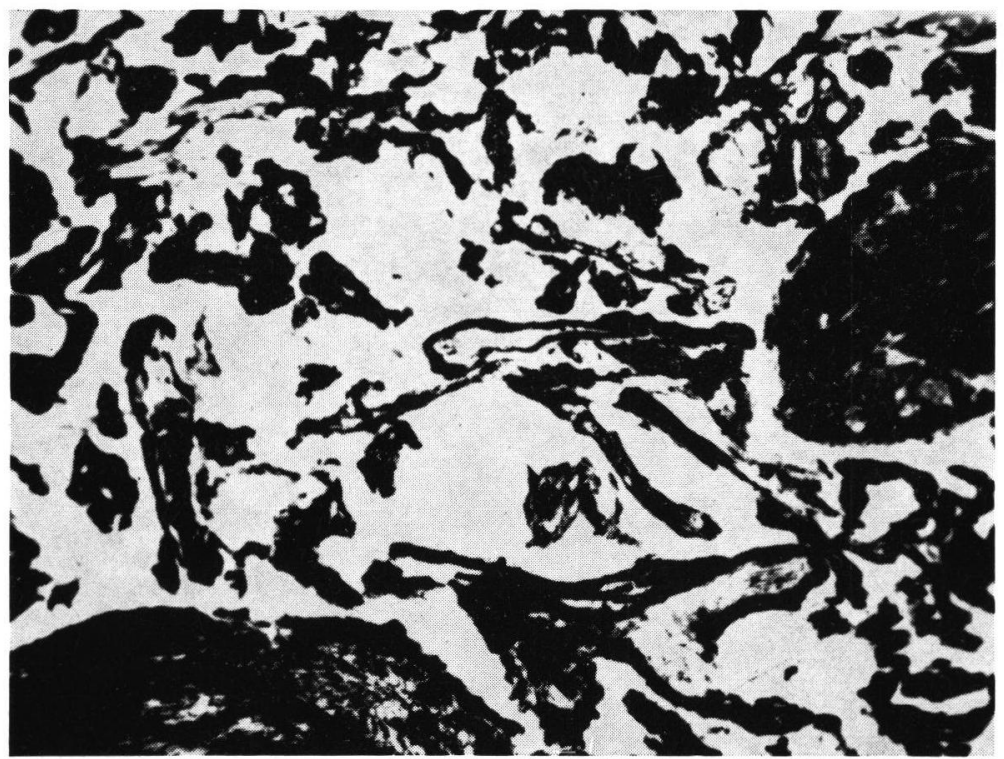

Abb. 2. Unreife Humusformen im A-Horizont einer Protorensina aus Holozäntravertin. Sivá Brada, Slowakei. Vergr. ca. 90 -fach.

Die Abstufung der Bodenvorkommen nach Alter und Verwitterungsgrad geht nicht nur auf die Abtragung, sondern auch auf die Sedimentation bzw. Überlagerung durch Lavadecken zurück.

Als Beispiel der ersten Möglichkeit seien Gebiete angeführt, die von Moränen verschiedener Vereisungen bedeckt sind. Verschiedenaltrige Moränen tragen Bodenbildungen, die 
sich voneinander sowohl typologisch als auch durch den Grad ihrer Verwitterung unterscheiden. Dasselbe trifft auch für die Lößdecken, Travertine sowie für vulkanische Bildungen verschiedenen Alters zu; z. B. kann in den Basaltgebieten Mitteleuropas auf verschiedenaltrigen Basaltdecken folgende Bodenreihe beobachtet werden: Rotlehm-BraunerdeRanker (vgl. KuBIËNA 1956 b).

Was das Holozän anbelangt, so gilt im allgemeinen, daß die meisten Flächen, auf denen die nacheiszeitlichen Böden ausgebildet sind, während des Jungpleistozäns entstanden, sei es frisches, durch junge Abtragung freigelegtes Anstehendes oder jungpleistozäne Ablagerungen.

Im Postglazial muß auch die Feinmodellation des Reliefs durch Landwirtschaft, als Eingriff des Menschen, in Betracht gezogen werden.

Aus dem Angeführten geht hervor, daß der Vergleich holoz ä ne r Bodenbildungen mit älteren Böden auf Hindernisse stößt, da die Gegenwart durch rasche Entstehung von Bodenresten sowie durch intensive Ablagerung anthropogener Bodensedimente in gegliederten Gebieten (z. B. rezente Lehmbröckelsande - KUKLA \& LOžEK 1961) gekennzeichnet ist. Für derartige Verhältnisse gibt es in der Vergangenheit kaum Analogie und wenn eine solche vorhanden ist, fällt sie in Zeitabschnitte mit einem abweichenden Klima, d. h. in die Kaltzeiten. Demgemäß weist der heutige künstliche Stand viele Phänomene auf, die den kaltzeitlichen und nicht den warmzeitlichen Verhältnissen entsprechen. Dies ist auf die Tätigkeit des Menschen zurückzuführen, die in der postglazialen Warmzeit den störenden Einfluß des kaltzeitlichen Klimas ersetzt (Lehmbröckelsandbildung, Aufschotterung - KUKLA \& LOŽEK 1961).

\section{Paläopedologische Provinzen}

Aus der geographischen Verbreitung der Böden und deren Veränderungen im Rahmen der einzelnen Regionen ergibt sich die bunte fazielle Ausbildung der Bodendecke. In klimatisch abweichenden Gebieten bilden sich synchron unterschiedliche Böden, während in verschiedenen Zeitabschnitten identische Böden in klimatisch entsprechenden Regionen entstehen. Als Beispiel können die Bodenzonen Nordeurasiens angeführt werden, obwohl sich es nur um eine grobe Zonengliederung handelt. Hingegen kann man in Mittel- und Westeuropa viel kompliziertere Verhältnisse beobachten, die durch viele Anomalien gekennzeichnet sind. Diese gehen auf folgende Faktoren zurück:

a) Position in Beziehung zum Ozean (Gebiete abnehmender Ozeanität)

b) Position in Beziehung zu den Gebirgen (Regenschatten etc.).

Verfolgt man die Beziehung der mitteleuropäischen Böden zu den klassischen Bodenzonen Osteuropas, so darf man nicht vergessen, daß in vielen Fällen keine identischen, sondern nur ähnliche Bodenbildungen vorliegen. Diese Unterschiede gehen auf das mehr ausgeglichene stärker ozeanische Klima des Westens zurück, das vor allem durch milde Winter gekennzeichnet ist (SMOLí́KovÁ \& LOŽEK 1965).

Aus dem Angeführten geht hervor, daß die dem Eichenmischwald entsprechende und durch das breite Tschernosemgebiet von der südlichen sog. „zimtfarbenen“ Waldbodenzone $^{1}$ ) der pontischen Gebirgswälder abgetrennte Drnopodsolzone gegen Westen mit dieser südlichen Zone allmählich zusammenläuft, während der Tschernosemgürtel gegen We-

1) Bei der Entstehung der Laubmischwaldböden („počvy širokolistvennych lesov“) ist die Sommertemperatur maßgebend (deshalb zieht sich diese Zone relativ weit gegen Nordosten); im Falle der zimtfarbenen südlichen braunen Böden („korycnevye pocvy“;) kommt der Wintertemperatur die Hauptrolle zu (deshalb biegt die Zone gegen Osten nach Süden ab). 
sten inselförmig auskeilt. In Mitteleuropa fließen bereits beide Zonen von braunen Böden zusammen. Sie bilden hier ein buntes Mosaik allmählicher Faziesänderung, die auf die zunehmende Ozeanität zurückgeht. Dieses Mischgebiet ist außerdem mit Tschernoseminseln durchsetzt, die an trockenste Bezirke gebunden sind. Demgemäß weist Mitteleuropa eine ganze Skala von braunen Bodenbildungen auf, deren Differenzierung nicht nur auf das abweichende Klima, sondern auch auf Relief- und Substrateinflüsse zurückgeht.

Die Tschernosemzone ist an niedrig gelegene ebene Gebiete mit Steppen- und Waldsteppenbeständen gebunden. Wie bereits gesagt, zerfällt der zusammenhängende ukrainischsüdrussische Tschernosemgürtel in Richtung Westen in isolierte Inseln, die im Karpatenund Wienerbecken, in den Mährischen Senken sowie in Innerböhmen, Thüringen und der Magdeburger Börde liegen. Hier klingen bereits die echten Tschernoseme aus. Ähnliche Bodenbildungen werden noch weiter gegen Westen gefunden (MücKENHAUSEN 1962), sie sind jedoch nicht mehr typisch und beschränken sich auf relativ kleine Flächen. Sie befinden sich alle in den Altsiedlungslandschaften.

Die mitteleuropäische (Para)braunerdezone, einschließlich der Bodenbildungen der wärmeliebenden submeridionalen Formationen (Flaumeichenbestände mit Kornelkirsche / Quercetum pubescentis mit Cornus mas L.), deren Nordgrenze sich durch Mitteleuropa zieht (Meusel 1943) nimmt vor allem die Hügelländer ein und entspricht der Zone von braunen und zimtfarbenen Böden im Süden der Sowjetunion, wo diese an den Gürtel der Buchenbestände und pontischen Wälder gebunden sind (südlich der Steppenzone).

Aus dem Vergleich der mitteleuropäischen Bodenverhältnissen mit der osteuropäischen Zonengliederung ergibt sich, daß in Mitteleuropa die Zonen der Laubmischwälder, der Steppe sowie der südlichen Wälder ausklingen, die sich hier in einem bunten orographisch und lokalklimatisch bedingten Mosaik durchsetzen. Falls man die osteuropäische Zonengliederung in Mitteleuropa anwenden will, muß man Anpassungen treffen, die die erwähnten Unterschiede berücksichtigen, und lediglich von entsprechenden, nicht von identischen Standorten und Böden sprechen.

Neben der Bodenzonierung im horizontalen Sinn (Zonengliederung) soll auch die entsprechende vertikale Gliederung (Stufengliederung) in Betracht gezogen werden, die in verschiedenen Höhenniveaus der Bergländer zum Vorschein kommt. Die Bodenverhältnisse sind in solchen Gebieten allerdings wesentlich komplizierter, da hier bunte Beziehungen ihren Ausdruck finden, die auf den Substrat- und Expositionswechsel zurückgehen.

Auch in der geologischen Vergangenheit waren Klimazonen vorhanden, denen bestimmte Bodenzonen entsprachen. Im Laufe der Zeit erfolgten Verschiebungen dieser Zonen im Sinne des zyklischen Klimawandels, was entsprechende Veränderungen des Bodenklimax an einem und demselben Standort zur Folge hatte. Eine Rekonstruktion von Bodenzonen und -provinzen in bestimmten Zeitphasen ist nur dort möglich, wo sich alte Bodenbildungen erhalten konnten. Günstige Verhältnisse bieten wiederum die Lößserien, in denen man direkt beobachten kann, welchem Wandel die Böden an einem Punkt unterworfen wurden. Man kann hier auch die Bodenprovinzen sowie die Höhenstufen unterscheiden. Mit diesen Problemen haben sich eingehender FInK (1956), KubIËNA (1956a, 1964) und BRUNNACKER (1958) befaßt.

In der von KuBIËNA vorgeschlagenen Zonengliederung nimmt eine problematische Stellung die sog. arktische Bodenprovinz ein, die als Analogon der kaltzeitlichen Verhältnisse angesehen wird. Es sei allerdings betont, daß KuBıËNA selbst erwähnt, daß der Löß in den gegenwärtigen arktischen Gebieten nicht auftritt. Der Terminus „arktisch" muß daher in diesem Falle lediglich als Hilfsbezeichnung betrachtet werden, da er nur eine Analogie betonen will, die auf die niedrige Temperatur zurückgeht. In Wirklichkeit waren die kaltzeitlichen Bedingungen in Mitteleuropa ziemlich abweichend, wie es floristische 
(Frenzel 1964, 1968) sowie faunistische Befunde (LožEK 1964 a, b) aus dem Löß zeigen. Dasselbe ergibt sich auch aus der Beschaffenheit des Substrats selbst. Für die Kaltzeit war vor allem ein kaltarides Binnenklima bezeichnend, dessen Analogie höchstwahrscheinlich in den trockenkalten Gebieten Ostsibiriens, z.B. in Jakutien zu finden sind (LuKAšEv 1961, Gerasimov 1964). In Anbetracht des Mangels eines modern bearbeiteten rezenten Vergleichsmaterials, müssen unsere kaltzeitlichen Bodenbildungen als eine völlig selbständige Bodengruppe bewertet werden, die im gegenwärtigen Europa keine Analogie besitzt.

Die Lößserien, auf die wir uns bei diesen Überlegungen vor allem stützen, belegen direkt, welchen Wandel die Bodenbildung auf demselben Substrat und Standort erfahren hat. Gleichzeitig lassen sie eine Gliederung nach den Bodenprovinzen und Höhenstufen erkennen.

\section{Tabelle 2}

Schemader Bodenbildung in verschiedenen Klimaphasen und Bodenzonen des Pleistozäns

\begin{tabular}{|c|c|c|c|c|}
\hline : & Hochglazial & Interglazial & $\begin{array}{l}\text { Interstadiale } \\
\text { des Frühglazials }\end{array}$ & $\begin{array}{l}\text { Wärmere } \\
\text { Schwankungen } \\
\text { des Hochglazials }\end{array}$ \\
\hline 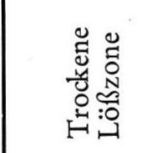 & $\begin{array}{l}\text { Löß } \\
\text { (Verlössung } \\
=\text { oblëssovanie) }\end{array}$ & Parabraunerde & Tschernosem & $\begin{array}{l}\text { Schwache braune } \\
\text { Bodenbildungen } \\
\text { („Entkalkungs- } \\
\text { zone") }\end{array}$ \\
\hline 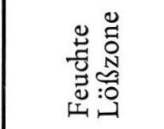 & $\begin{array}{l}\text { Löß (oft z. T. } \\
\text { entkalkt) } \\
\text { (Verlössung) }\end{array}$ & $\begin{array}{l}\text { Pseudovergleyte } \\
\text { Parabraunerde }\end{array}$ & $\begin{array}{l}\text { Schwach } \\
\text { ausgebildete } \\
\text { Braunerde }\end{array}$ & $\begin{array}{l}\text { „Naßboden“ } \\
\text { (pseudovergleyte } \\
\text { Entkalkungszone) }\end{array}$ \\
\hline 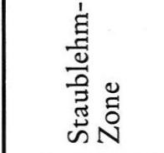 & $\begin{array}{l}\text { Staublehm } \\
\text { („Verlehmung } \\
=\text { oglinenie“) }\end{array}$ & $\begin{array}{l}\text { Pseudogley (stark } \\
\text { ausgebildet) }\end{array}$ & $\begin{array}{l}\text { Pseudogley aus } \\
\text { schwacher } \\
\text { Braunerde }\end{array}$ & $\begin{array}{l}\text { Pseudogley aus } \\
\text { Naßboden }\end{array}$ \\
\hline 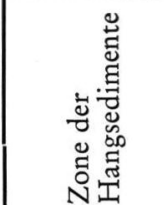 & $\begin{array}{l}\text { Hangsedimente } \\
\text { mit grobklasti- } \\
\text { scher Komponente } \\
\text { (Bodenbildung } \\
\text { gestört) }\end{array}$ & $\begin{array}{l}\text { Braune Böden } \\
\text { Semipodsole } \\
\text { etc. }\end{array}$ & $\begin{array}{l}\text { Schwach entwik- } \\
\text { kelte Bodenbil- } \\
\text { dungen (Ranker) }\end{array}$ & Bodenfließen \\
\hline
\end{tabular}

Die Grenzen zwischen den paläopedologischen Provinzen der einzelnen Interglaziale und den Bodenprovinzen der Gegenwart decken sich nur im groben Rahmen.

Die Abweichungen sind vor allem aus dem Vergleich der rezenten und in tergla zi a len Bodenbildungen der Lößserien ersichtlich. Dort, wo heutzutage Ts cher nos e me vorherrschen (meist mehr oder weniger degradiert), ist das letzte Interglazial üblicherweise durch eine typische $\mathrm{Parabraunerde} \mathrm{vertreten} \mathrm{(Innerböh-}$ men, Südmähren - z. B. im klassischen Aufschluß von Dolní Věstonice). Wie bereits erwähnt, kann die Erklärung dieses Unterschieds in der ab weichenden Entwick- 
lung während des Postglazials gesucht werden, d. h. vor allem im langfristigen Einfluß der bäuerlichen Besiedlung der Neolithiker, die bereits im Atlantikum beginnt (5. Jahrtausend v. Chr.). und einen ausschließlich für die Nacheiszeit bezeichnenden Eingriff darstellt, der in den älteren Warmzeiten keine Analogie hat.

Was der Vergleich der jungpleistozänen Böden mit den älteren anbelangt, können wir bisher mit Sicherheit sagen, daß in den altpleistozänen Warmzeiten und vor allem im Jungtertiär eine starke Rubefikationstendenz herrschte - namentlich im pannonischen Raum (SMolíková 1967, Bronger 1969). Auch die Tirsifikation ist in dieser Zeitspanne vertreten, hingegen sind humose Steppenböden vom Tschernosemtypus fast unbekannt.

Eine Rekonstruktion von paläopedologischen Provinzen ist mit der Rekonstruktion von Vegetations zonen praktisch identisch. Diese kann sich auf die heute bereits zahlreich vorhandenen paläobotanischen Funde stützen (vgl. Frenzel 1964, 1968), die auch für die Paläopedologie weitere wertvolle Kriterien bieten.

Außer den Lößböden können für solche Zwecke auch Böden auf Karbonat- oder wenigstens kalkhaltigen Gesteinen herangezogen werden, die heute schon ziemlich gut bekannt sind.

Unter den Karbonatböden sind folgende von höchster Bedeutung:

a) Böden bzw. Bodensedimente in den Hangserien der Karstlandschaften

b) Bodenbildungen auf den Binnenwasserkalken („Travertinen“).

Was die Bodenbildungen im Bereiche der karbonathaltigen Gesteine anbelangt, sind die Böden in den Hangbildungen der mesozoischen und tertiären Mergelgebiete an erster Stelle zu nennen.

Die relativ zahlreichen Vorkommen dieser Böden, die nicht nur typologisch gut bestimmbar sind (Rendsinen und Terrae calcis), sondern oft auch mit Fossilien korreliert werden können, erlauben es, die ehemalige Verbreitung einzelner Bodentypen sowie deren Wandlungen während der Warmzeiten zu rekonstruieren.

Hingegen sind andere Bodentypen im fossilen Zustand praktisch nicht erfaßbar, was vor allem für verschiedene Podsole und andere Silikatböden gilt. Hier kann sich die Rekonstruktion nur auf Analogien stützen.

Eine verläßliche Kenntnis der paläopedologischen Provinzen bzw. der ehemaligen Bodenfaziesbereiche bietet die notwendige Grundlage nicht nur für eine richtige Rekonstruktion der einstigen Bodenverhältnisse, sondern ist auch von grundsätzlicher Bedeutung für die Quartärstratigraphie.

\section{Die paläogeographische und paläoklimatische Bedeutung der Böden}

Wenn auch bisher als beste Anzeiger der ehemaligen Klima- und Umweltverhältnisse zweifellos die Fossilien betrachtet werden müssen (LOžEK 1966), so kommt in dieser Hinsicht doch auch den Paläoböden eine hervorragende Rolle zu. Die Fossilfunde sind nämlich im Vergleich mit den weitverbreiteten Paläoböden relativ selten und oft nur von lokaler Bedeutung. Hingegen stellen die alten Böden Bildungen dar, die über große Flächen verfolgt werden können, so daß sie geeignete Stützen für die obenerwähnten Rekonstruktionen bieten.

Für landschafts- und klimageschichtliche $Z$ wecke sind im Falle der Paläoböden folgende zwei Kriterien von Bedeutung:

A: Pedologische Kriterien

B : Korrelation mit Fossilfunden. 


\section{Pedologische Kriterien}

Bei einer klimatischen Würdigung kann im Falle der alten Böden die Analogie mit den rezenten Bodenbildungen herangezogen werden, wobei folgende Voraussetzungen zu beachten sind:

1. Eine vollkommene typologische Identität der alten Böden mit entsprechenden rezenten Bodentypen,

2. Eine verläßliche Kenntnis der betreffenden Standortverhältnisse.

1. Im ersten Falle muß man sich auf eine möglichst präzise Bestimmung und $\mathrm{Aus}$ wertung stützen und jede grobe Generalisation vermeiden, was am besten auf Grund mikromorphologischer Untersuchungen möglich ist. Außerdem sei betont, daß die untersuchten Böden in a tochthoner oder höchstens parautochthoner Position auftreten müssen.

2. Jedem rezenten Bodentyp entspricht ein bestimmter OKotyp, d. h. ein natürlicher Standort und nur von diesem kann die Rekonstruktion für paläopedologische Zwecke ausgehen.

In der Quartärkunde fanden vor allem die Lößböden viel Beachtung. Dies bringt folgende Vorteile mit sich:

a) Sehr einheitliches, auf eine Klimazone gebundenes Substrat,

b) Auftreten von Böden verschiedener paläopedologischer Provinzen an einer Fundstelle,

c) Verschiedene typologische Angehörigkeit der Böden an einem Fundpunkt, die einen hinreichenden Beleg für den klimabedingten Wandel der Umweltfaktoren bietet.

Als Beispiel kann das Hauptpaar der fossilen Lößböden angeführt werden:

Die Tschernoseme (und Paraendsinen) wurden lange als Zeugen eines warmzeitlichen Klimas angesehen (J. Pelíšex 1949, K. Žebera 1949), obwohl ihre Temperaturspanne viel weiter ist. Sie entsprechen dem Steppenklima. Nach Aussage der Fauna fallen sie in die Phasen eines trockenen Klimas, das sehr große Temperaturschwankungen aufweist und daher nicht einfach als „warm“, sondern höchstens als sommerwarm bezeichnet werden kann. Es hat sich herausgestellt, daß sie vor allem für wärmere Schwankungen zweiten Ranges, also für bestimmte Interstadiale charakteristisch sind (Abb. 3 ). Diese Feststellung bezieht sich allerdings nur auf die ple is to z än en Tschernoseme, da die holozänen unter anderen Bedingungen entstanden sind, wovon die eingebettete Weichtierfauna klar zeugt (SмоLíková \& LožEK 1964). Die Holozäntschernoseme bildeten sich auch unter warmem und zeitweise ziemlich feuchtem Klima, da die betreffenden Gebiete dank dem Eingriff des Menschen unbewaldet und steppenartig blieben. Die holozäne Tschernosemfauna unterscheidet sich demgemäß von den Fossilbeständen aus den pleistozänen Tschernosem durch die Anwesenheit vieler wärmebedürftiger Schneckenarten, die im Pleistozän praktisch fehlen und deren Einzug nach Mitteleuropa nur auf die außerordentlichen Umweltbedingungen der Nacheiszeit zurückzuführen ist (sog. moderne Steppenarten - LOžEK 1964a).

Die illimerisierten Bodenbildungen entsprechen hingegen einem langfristig wirkenden warmfeuchten Klima und sind unter Wald gebildet worden. In den Lößserien charakterisieren sie somit die echten Warmzeiten, d.h. die Interglaziale (SMolíková \& LožeK 1965).

Es sei betont, daß von den stark verwitterten illimerisierten Böden verschiedene schwach verwitterte braune Bodenbildungen (meist Entkalkungszonen mit mäßiger Oxidation und 


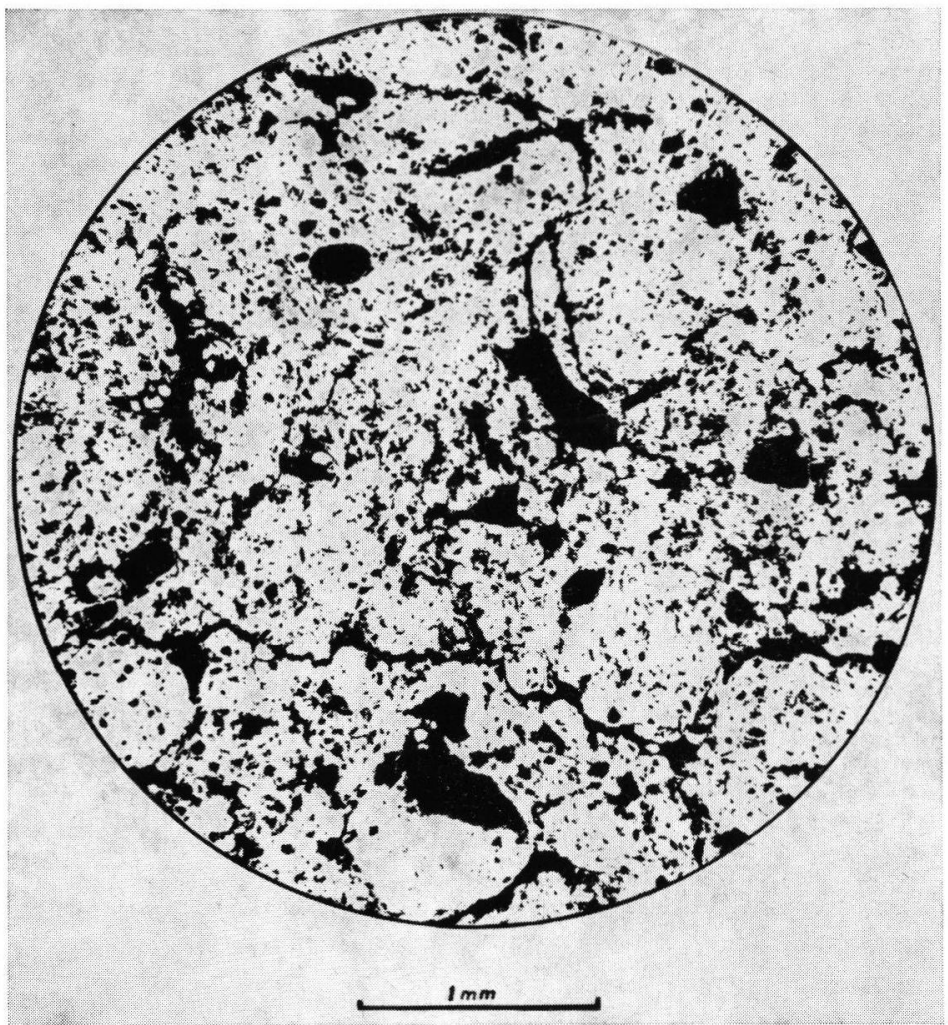

Abb. 3. Charakteristisches Schwammgefüge eines typischen Tschernosems. - A-Horizont der unteren Bodenbildung von PK II („W 1/2") in Modřice bei Brünn. Vergr. ca. 100-fach.

Pseudovergleyung) scharf unterschieden werden müssen. $\left.{ }^{2}\right)$ Sie entsprechen den w ä r m e ren Oszillationen der pleniglazialen Abschnitte und werden üblicherweise mit Bodenbildungen der Tundra ${ }^{3}$ ) verglichen („arktische Braunerden, initiale Pseudogleye“ usw.).

Von ähnlicher Bedeutung sind auch die Terrae-calcis-Böden. Während die Terra fusca ein dem gegenwärtigen ähnliches Klima anzeigt, das allerdings langfristig wirken muß (oft polyzyklische Bodenbildungen!), stellt die Terra rossa immer einen Beweis für ein wärmeres, wechselfeuchtes Klima submediterraner Prägung dar. Im mitteleuropäischen Pleistozän ist die Terra rossa bisher nur aus den ältesten Warmzeiten bekannt, als in Mitteleuropa noch eine Fauna und Flora mit vielen südlichen Elementen vorhanden waren (vgl. KRETZOI 1956).

Entsprechend können auch weitere Bodentypen bewertet werden, die allerdings zum Unterschied von den Löß- und Karbonatböden nur selten erhalten bleiben.

2) Was leider nicht immer der Fall war, so daß viele ältere Beschreibungen keine genauere Auswertung erlauben!

3) Zum Terminus "Tundra“ kann in diesem Zusammenhang dasselbe gesagt werden, was bereits beim Terminus „arktisch“ erwähnt worden ist (s. S. 164). 


\section{Korrelation mit Fossilfunden}

Für die Korrelation paläontologischer Funde mit den fossilen Bodenbildungen sind zwei Fossiliengruppen von Bedeutung:

1. Pflanzenreste,

2. Konchylien.

1. Die Pflanzenreste sind in den Böden meist in Form von Pollenkörnern vertreten. Diese erhalten sich in großen Mengen zwar nur in einigen günstigen Fällen, die bisherigen Pollenanalysen bieten jedoch so gute Ergebnisse (Frenzel 1964, 1968), daß man sie zur Rekonstruktion eines Gesamtbildes der anliegenden Landschaft heranziehen kann.

Außerdem führen die Paläoböden oft Holzkohlen (Beil. III, Abb. 1) und zuweilen auch $\mathrm{Früch}$ te, vor allem von Celtis (Mittelpleistozäne Bodenbildungen der innerböhmischen Lößserien, Terra rossa-Sedimente in Karsthohlräumen). Viel günstiger sind allerdings die Sumpfböden, in denen verschiedene Makroreste, namentlich die Samen erhalten bleiben.

Ergänzend seien noch die Pfla n zenopale (WERner 1960) bzw. andere Neubildungen erwähnt, wie z. B. verschiedene Typen von Wurzelkonkretionen.

2. Die Molluskengeh ä u s können sich allerdings nur im kalkhaltigen Material erhalten, so daß man sie nur in primär kalkhaltigen Böden, z. B. Karbonattschernosemen und Rendsinen, finden kann. Die Konchylien wurden nach dem Absterben der Tiere von

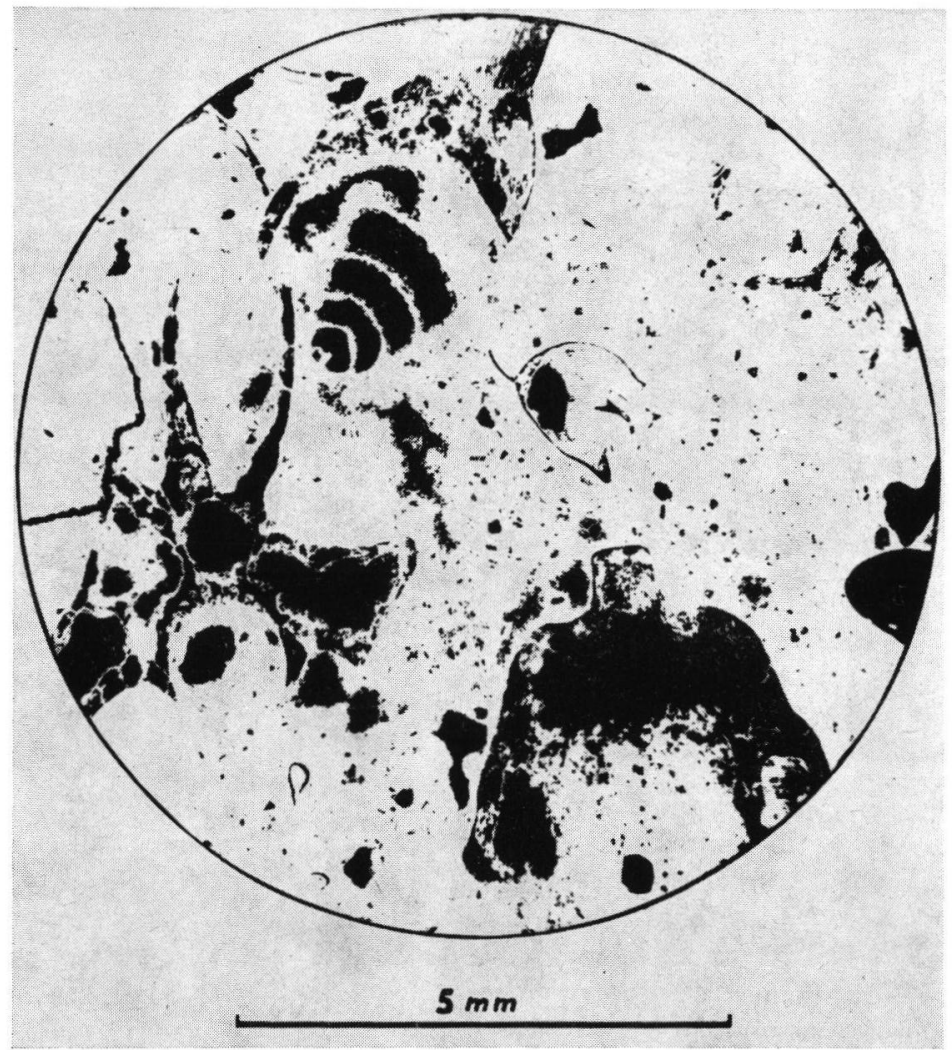

Abb. 4. Schneckengehäuse und Schlangenwirbel in verfestigten Terra rossa-Sedimenten altpleistozänẹn Alters, - Chalmová, Mittelslowakei. 
der Oberfläche in tiefere Bodenhorizonte durch die Tätigkeit der Bodenbewohner (Kleinsäuger, Würmer) sekundär eingeschleppt. Ihre Fossilisierung ist also mit der biologischen Perstruktion des A-Horizontes direkt verknüptt.

Die Konchylien sind im Durchschnitt viel seltener als die Pollen. Für paläopedologische Zwecke sind sie jedoch von höchstem Wert, da sie eine Rekonstruktion der U m w elt verhältnisse direkt a n Ort und Stelle ermöglichen (Ložek 1964a, 1969).

Außer den konchylienführenden autochthonen und parautochthonen Bodenbildungen sind die Mollusken auch in den kalkhaltigen Boden s e dime n t e n reichlich vorhanden, was günstige Möglichkeiten vor allem dort bietet, wo sich eine rasche Sedimentation des Bodenmaterials vollzog, die die einzelnen Stadien der Bodenentwicklung erkennen läßt. Es handelt sich vor allem um Bodensedimente in den Hangablagerungen und Höhlenausfüllungen der Karstgebiete (Abb. 4), also in Gegenden, die nicht nur sehr molluskenreich sind, sondern auch günstige Bedingungen für die Erhaltung von alten Bodenbildungen bieten, die hier außerdem auch mit den Vertebratenfunden korreliert werden können (Abb. 5).

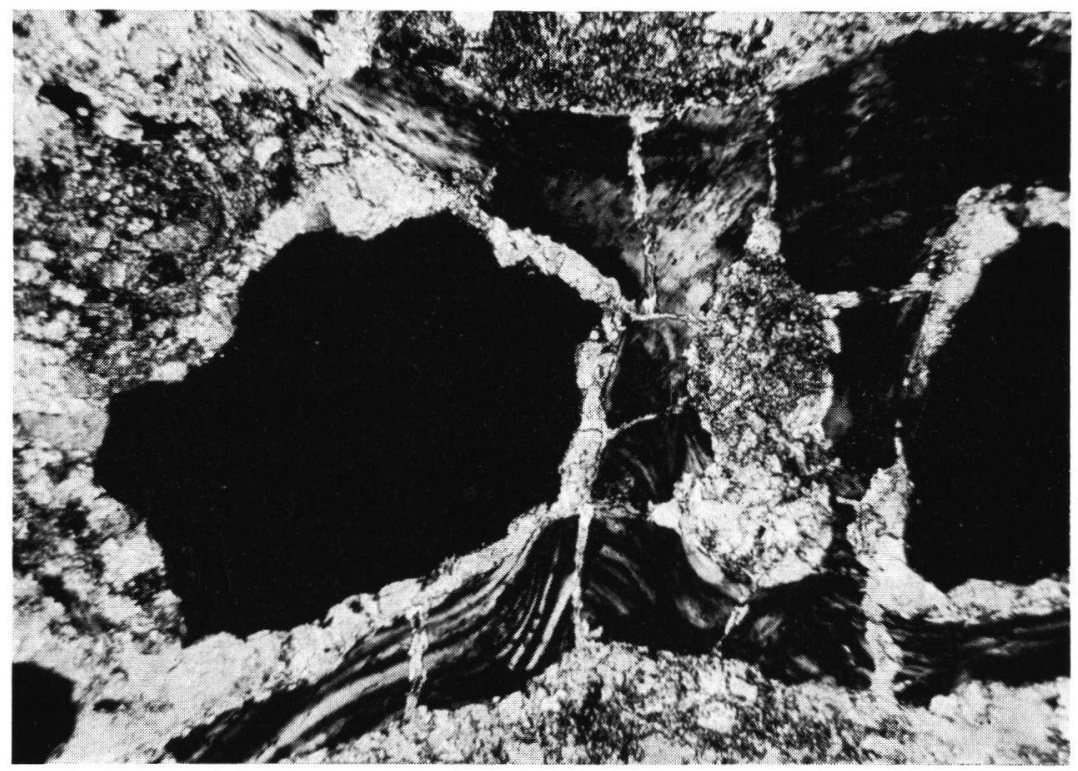

Abb. 5. Schlangenwirbel in Sedimenten einer allitischen Terra rossa (vermutlich neogenen Alters). Chalmová, Mittelslowakei. - Gekreuzte Nikols. Vergr. ca. 90-fach.

Sehr charakteristisch sind Terra rossa-Sedimente in vertikalen Karsthohlräumen, Klüften und Schloten, die an vielen Stellen altpleistozäne Knochen und zuweilen auch Konchylien führen (Kretzoi 1956, Fejfar 1961, Dehm 1961, Ložek \& Skřivánek 1966).

Vom bodenzoologischen Gesichtspunkt aus ist es bemerkenswert, daß auf Grund der Mikromorphologie praktisch in allen Lößböden eine fossile bi ologische Tätig $\mathrm{k}$ e it nachgewiesen werden kann. Es wurde beispielsweise festgestellt, daß der Anteil der auf die Wirkung des Edaphons zurückgehenden Kleinhohlräume zwischen 20-85\% schwankt. Die Stabilität solcher Spuren hängt vermutlich von deren besonderen chemischen und physikalischen Eigenschaften $\mathrm{ab}$, die dem biologisch nicht angegriffenen Bodenmaterial offenbar fehlen. Überraschend ist der Nachweis von zahlreichen Bodentierspuren auch in den ältesten pleistozänen Bodenbildungen (SMoLíková 1967); es handelt sich meist um Exkremente (ZACHARIAE 1967). Jedenfalls sollte man diesen Erscheinungen viel mehr Auf- 
merksamkeit widmen als bisher, damit man sie in Zukunft für paläopedologische und

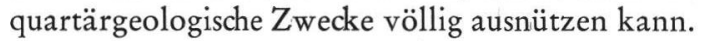

Im Falle von Bodensedimenten ist jedoch zu beachten, daß die Auswertung in Korrelation mit paläontologischen Funden mit entsprechender Vorsicht durchgeführt wird, und zwar aus folgenden Gründen:

1. Die a tochthone und allochthone Fossilienkomponente muß unbedingt auseinander gehalten werden. Als autochthon werden solche Fossilreste angesehen, die bereits im Material des ursprünglichen Bodens fossilisiert wurden und somit den ehemaligen Boden charakterisieren. Solche Fossilien können allerdings nur in Sedimenten von primär kalkhaltigen Böden auftreten. In stark verwitterten, entkalkten Bodenbildungen gibt es keine Faunenreste, so daß ihre Sedimente nur Fossilien führen können, die bei der Ablagerung des Bodensed:ments eingebettet wurden ${ }^{4}$ ) und daher allochthon sind (Abb. 6).

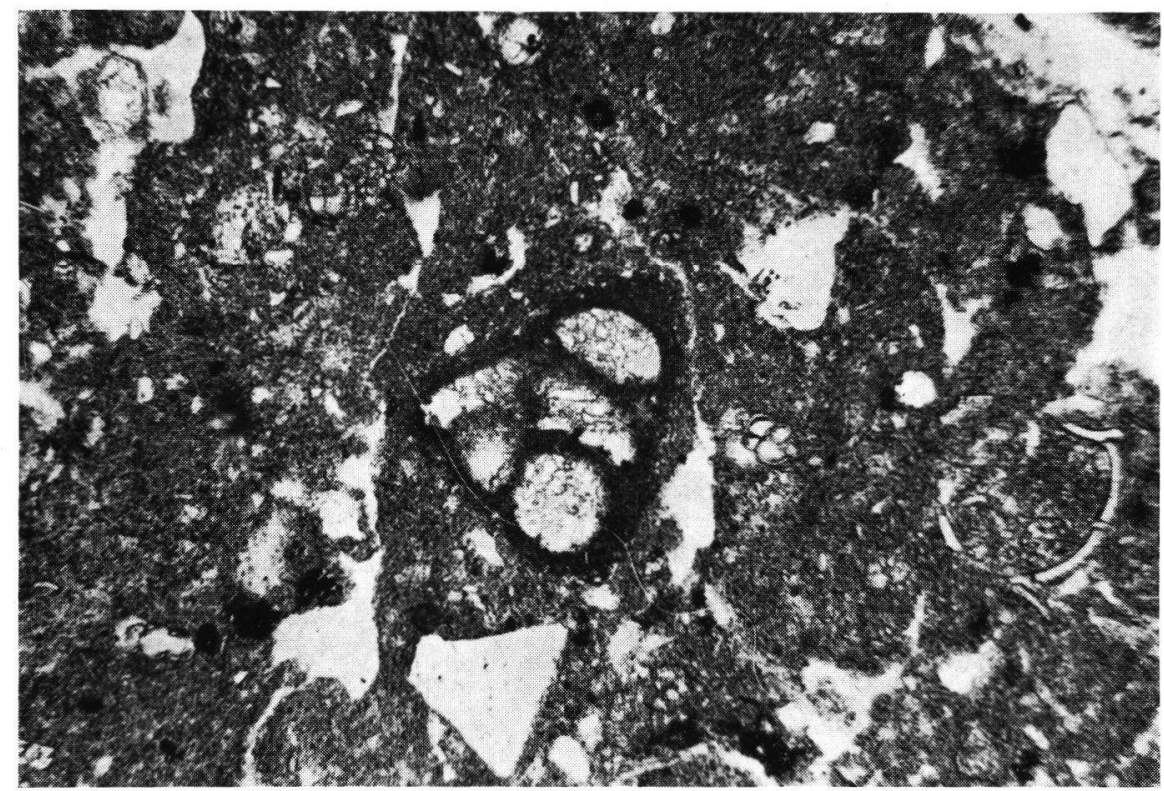

Abb. 6. Kreideforaminiferen als allochthone Komponente im braunlehmartigen Reliktboden aus Basalt-Feinschutt. — Litoměřice (Leitmeritz) III, Böhmisches Mittelgebirge. Mikrophotos L. Sмоцí́кои́.

2. Die Retardation, d. h. diejenige Zeit, welche die Ablagerung des Bodensediments von der Bildung des ursprünglichen Bodens trennt, kann verschieden lang sein. Hier sind feinstratigraphische Untersuchungsmethoden heranzuziehen. Als Beispiel können Terra rossa-Sedimente in Karsthohlräumen angeführt werden, die nach Aussage der eingebetteten Fauna zweifellos in den Kaltzeiten abgelagert wurden (vgl. Punkt 1).

In derartigen Fällen soll man sich stets auf eine größere Zahl von Befunden stützen, da erst auf Grund eines statistischen Vergleichs die gesetzmäßigen Beziehungen von eventuellen Anomalien zu unterscheiden sind. So sind z.B. die altpleistozänen Karstfaunen praktisch ausnahmslos an Bodensedimente gebunden. Falls hochwarmzeitliche Gemein-

4) Die Termini autochthon bzw. allochthon sind hier in paläopedologischer Auffassung verwandt, die von der rein paläontologischen Terminologie weitgehend abweicht (vgl. V. LožEK 1964a). 
schaften vorliegen, sind sie meist in Terra rossa-Sedimenten eingebettet - auch dort, wo heute bzw. im Jungpleistozän keine Terra rossa-Böden vorhanden sind. Daraus kann geschlossen werden, daß für die altpleistozänen Warmzeiten die Terra rossa bezeichnend war. Im allgemeinen läßt der Fossilgehalt erkennen, daß den schwachen Bodenbildungen der Phase 1 (vgl. Tab. 1) helle, stark kalkhaltige, oft versinterte Sedimente entsprechen, die von braunen bis roten lehmigen Schichten (Terra rossa-Sedimente im Altpleistozän) überlagert sind; diese sind für die Hochwarmzeit charakteristisch. Das oberste Glied solcher Serien sind meist dunkle humose Lehme mit Schutt, die als Äquivalent der frühglazialen Humusböden zu betrachten sind (dies gilt sowohl für das Cromer-Interglazial als auch für das Eem oder die Nacheiszeit).

Erst eine richtige Anwendung der Kenntnisse von rezenten Böden sowie die Korrelation mit dem Fossilgehalt machen eine volle Ausnutzung der fossilen Böden möglich (z. B. im Bereich der Lößserien die Unterscheidung von Steppen-, Kaltsteppen-, Taiga- und Laubmischwaldböden), auf die sich weitgehende landschaftsgeschichtliche Rekonstruktionen stützen können (z. B. die Zonengliederung im Frühglazial usw. - vgl. SMolíková \& LožEk 1965).

\section{Stratigraphische Bedeutung der Böden}

Aus den Beziehungen der Böden zum Klima ergibt sich auch die stratigriphische Bedeutung der Bodenbildungen, da auch die meisten quartärgeologischen Systeme auf den Klimawandel gestützt werden. In der stratigraphischen Forschung finden die Böden zweierlei Anwendung:

1. Als makroskopisch auffallende Trennhorizonte der terre$s \mathrm{t} r$ is chen A blage rungs folgen. In bestimmten Sedimentkomplexen, z. B. in den Lößserien, stellen die Paläoböden die einzigen Stützpunkte dar, die die stratigraphische Unterscheidung einzelner Lößdecken ermöglichen. In dieser Hinsicht spielen die Bodenkomplexe eine hervorragende Rolle, da sie die bedeutsamsten pedostratigraphischen Einheiten darstellen. Es handelt sich oft um Stratotype, die eine gesetzmäßige Ausbildung aufweisen und auf die sich die regionale Parallelisierung stützen kann (z. B. Stillfrieder Komplex von Fink 1954, 1956).

Bei der stratigraphischen Anwendung der Bodenkomplexe sind folgende Voraussetzungen zu erfüllen:

a) Genaue topographische Umgrenzung bestimmter typologisch eingehend ausgewerteten Bodenabfolgen,

b) Ausgliederung der einzelnen Regionen und deren gegenseitige Korrelation,

c) Sämtliche Schlüsse müssen sich lediglich auf volla usgebildete Bodenkomplexe stützen (unvollkommene Bodenabfolgen, Erosionsreste usw. sind auszuscheiden!).

2. Als Indikatoren der Intensität von einzelnen Wärme$\mathrm{sch}$ wankungen. Als deutliche stratigraphische Leithorizonte sind die Böden auch vom Gesichtspunkt der Chronologie aus von hoher Bedeutung. Vollausgebildete fossile Parabraunerden entsprechen z. B. stets einem In te $\mathrm{rg}$ la z i a l, während Tschernoseme bzw. Rendsinen nur kleineren Schwankungen (I n t e r s t a d i a l e n) entsprechen können. Falls in einem Lößprofil, das sonst keine stratigraphischen Kriterien bietet, eine Parabraunerde auftritt, so kann man schließen, daß die Parabraunerde dem letzten Interglazial bzw. einer älteren Warmzeit entspricht; jüngere Phasen sind jedoch ausgeschlossen. Eine eingehendere Einordnung ist heute anhand der mikromorphologischen Untersuchung schon möglich. 
Ähnlich liegen die Dinge auch im Falle der Te r r a e c a l c is - Böden und P las t osole. Es wurde festgestellt, daß allit ische Terra rossa in Mitteleuropa dem Jungtertiär entsprechen, während siallitische Terra rossa und einige Übergangsformen noch in den ältestpleistoz änen Warmzeiten gebildet wurden. Eine vollausgebildete Te r r a f u s c a gehört zu typischen Produkten der In ter$\mathrm{g} \mathrm{l} \mathrm{a} \mathrm{z} \mathrm{i} \mathrm{a} \mathrm{l} \mathrm{e,} \mathrm{fehlt} \mathrm{jedoch} \mathrm{völlig} \mathrm{den} \mathrm{Interstadialen,} \mathrm{während} \mathrm{in} \mathrm{der} \mathrm{Nacheiszeit} \mathrm{nur} \mathrm{unvoll-}$ kommen ausgebildete Formen entstehen, da die zur Verfügung stehende Bildungsfrist zu kurz ist (SMOLíkovÁ \& LožEK 1962).

Ein entsprechendes Bild der Bodenentwicklung bieten auch die $\mathrm{B}$ a s a $1 \mathrm{te}$. Während die gegenwärtigen Basaltböden typologisch den Rankern und eutrophen Braunerden entsprechen, erreichen die altpleistozänen und jungtertiären Bodenbildungen aus Basalt das R o t l e h m s t a di u m (KubiënA 1956b).

Wenn auch die Böden nur grobe stratigraphische Abschätzungen erlauben, so stellen sie doch einen der bedeutsamen Anhaltspunkte dar, da sie im Gelände deutlich sichtbar sind, leicht untersucht werden können und auf g roßen Flächen auftreten.

In Anbetracht dieser Sachlage gibt es eine ganze Reihe Versuche, auf Grund der Böden grobstratigraphische Systeme aufzustellen. Diese Methoden, die sich oft nur auf die typische Färbung stützen, wurden vor allem im Mittelmeergebiet angewandt (z. B. Südfrankreich Alimen 1955, Marokko - KLINGE 1958). Entsprechende Ergebnisse können auch aus den Bodenuntersuchungen auf verschiedenaltrigen Travertinen (SMOLíkovÁ \& LožEK 1962), in den Hangablagerungsfolgen, in den Ausfüllungen der Karsthohlräume (Kretzor 1956, SMolíková 1963b) sowie in mächtigen, viele Zyklen umfassenden Lößserien (LIU TungSHeNg - Chang Ttung-Hu 1964) erbracht werden.

Heutzutage befinden sich diese Methoden erst im Anfangsstadium ihrer Entfaltung. Als Voraussetzung ihrer erfolgreichen Anwendung ist an erster Stelle eine möglichst genaue beschreibende Erfassung von einzelnen Bodentypen zu nennen, da die älteren bodengenetischen Systeme so grobe Verallgemeinerungen darstellen, daß sie den Anforderungen der gegenwärtigen stratigraphischen Geologie nicht gerecht werden können.

\section{Schluß}

Die Problematik der Quartärböden kann ausschließlich auf Grund eines $\mathrm{n}$ a $\mathrm{t} \mathrm{u} \mathbf{r} \mathrm{w}$ is senschaftlichen Systems der gegenwärtigen Bodenbildungen gelöst werden, das die pedologischen Verhältnisse an sämtlichen Standortstypen berücksichtigt und auf die vom Menschen ungestörten Bodenvorkommen gestützt wird.

Im Grunde genommen ist die Bodenentwicklung während des Quartärs durch eine komplizierte Polygenese gekennzeichnet. Die geläufigen, meist rein analytischen Untersuchungsmethoden der bisherigen bodenkundlichen Praxis sind nicht imstande, weder das Gesamtbild noch die einzelnen Entwicklungsstadien einer Bodenbildung zu erfassen. Über diese Möglichkeiten verfügt jedoch die Bodenmikromorphogie. Die Einführung der mikromorphologischen Methoden in die Quartärforschung erfolgte allerdings erst in der jüngsten Zeit, so daß die zur Verfügung stehenden Angaben noch größtenteils auf die Ergebnisse der analytischen Methoden und zuweilen nur auf Geländebeobachtungen gestützt werden. Im Hinblick auf diese kurze Zeit konnte nur ein Bruchteil der bisherigen Kenntnisse kritisch umgewertet werden.

Aus der Korrelation der Böden mit dem klimabedingten Sedimentationszyklus des Quartärs ergeben sich sehr deutliche Gesetzmäßigkeiten der Bodenentwicklung, die den einzelnen Phasen des Zyklus entsprechen. 
Aus der Beziehung der Böden zur Abtragung und Sedimenta$\mathrm{t}$ a $\mathrm{t}$ i o $\mathrm{n}$ geht hervor, daß die rezenten Böden meist nur schwer mit den alten verglichen werden können, da für die Gegenwart eine rasch verlaufende Bildung von Bodenresten und zugleich eine intensive Akkumulation von Bodensedimenten beze:chnend ist. Diese anthropogen bedingten Verhältnisse erinnern viel mehr an die Kaltzeiten als an die ruhigen Interglaziale. Der störende Einfluß des Glazialklimas wird in der Nacheiszeit durch die Tätigkeit des Menschen ersetzt (Entwaldung und Ackerbau).

Auf Grund der Rekonstruktion der palä o pedologischen Provinzen sowie der Bodenfazies im allgemeinen können die Bodenverhältnisse in den ehemaligen Klimazonen im Laufe des Klimawandels verfolgt werden. Eine Feststellung von Bodenzonen und -provinzen für verschiedene Phasen des klimabedingten Sedimentationszyklus ist nur dort möglich, wo sich die alten Böden erhalten können. Im groben Rahmen entspricht die Rekonstruktion von paläopedologischen Provinzen der Rekonstruktion von Vegetationszonen.

Jede landschafts- und klimageschichtliche Würdigung der Paläoböden muß sich einerseits auf pedologische Kriterien, d. h. auf die genaue typologische Identität der alten und rezenten Bodenbildungen sowie auf die Korrelation der betreffenden rezenten Böden mit dem Standort stützen, andererseits muß sie in einzelnen Bodenbildungen eingebetteten Fossilfunde in Betracht ziehen.

Die Paläoböden stellen ausgezeichnete Trennhorizonte in terristrischen Ablagerungsfolgen dar, die zugleich die Intensität und Länge der betreffenden Klimaschwankungen erkennen lassen. Sie sind demgemäß von erstrangiger Bedeutung für die Quartärstratigraphie und werden mit Recht als pedostratigraphische $\mathrm{E}$ in he it e $\mathrm{n}$ bezeichnet.

\section{Literatur}

Alimen, H.: Colorimétrie de sédiments quaternaires et paléoclimats. Premiers résultats. - Bull. Soc. géol. Fr., 6e Série, 4, fasc. 7-9, 609-619, 1955.

Bronger, A.: Lösse, ihre Verbraunungszonen und fossile Böden. Ein Beitrag zur Stratigraphie des oberen Pleistozäns in Südbaden. - Schriften des Geograph. Instituts der Universität Kiel, 24, 114 S., Kiel 1966.

- : Zur Klimageschichte des Quartärs von Südbaden auf bodengeographischer Grundlage. Petermanns Geogr. Mitt., 113, 2, 112-124, Gotha 1969.

BrunNacker, K.: Zur Parallelisierung des Jungpleistozäns in den Periglazialgebieten Bayerns und seiner östlichen Nachbarländer. - Geol. Jb., 76, 129-150, 1958.

— : Schätzungen über die Dauer des Quartärs, insbesondere auf der Grundlage seiner Paläoböden. - Geol. Rundsch., 54, 1, 415-428, 1965.

Dенм, R.: Spaltenfüllungen als Lagerstätten fossiler Landwirbeltiere. - Mitt. d. Bayer. Staatssammlung, Paläont.-hist. Geologie, 1, 57-72, München 1961.

FEDOROFF, N.: Les pedogeneses quaternaires en France. - Lab. de geol.-pedol., de L'E.N.S.A. de Grignon, 1969.

FEJFAR, O.: Die plio-pleistozänen Wirbeltierfaunen von Hajnáčka und Ivanovce (Slowakei), ČSR. I. Die Fundumstände und Stratigraphie. - Neues Jb. Mineral. Geol. Pal., 111, 3, 257-273, 1961.

FINK, J.: Die fossilen Böden im österreichischen Löß. - Quartär (Quartär Jb. Erforsch. Eiszeit.), 6, 85-108, 1954.

— : Zur Systematik fossiler und rezenter Lößböden in Ớsterreich. - Sixième Congrès Internat. de la Science du Sol, 585-592. Paris 1956.

Franz, H.: Beiträge zur Kenntnis der Bodenentwicklung in NW-Spanien auf Grund fossiler Böden. - Anales de Edaf. y Agrobiol., 26, 1-4, 33-51, Madrid 1967.

Frenzel, B.: Zur Pollenanalyse von Lössen. - Eiszeitalter u. Gegenwart, 15, 3-39, Öhringen 1964.

- : Grundzüge der pleistozänen Vegetationsgeschichte Nord-Eurasiens. — Erdwissenschftl. Forsch., 1, Wiesbaden 1968. 
Gerasimov, I. P.: Loess Genesis and Soil Formation. - Rep. af the VIth Internat. Congress on Quaternary, Warsaw 1961, Vol. IV - Periglacial and Archaeological and Anthropological Sections and Symposium on Loess, 463-468, Lódź 1964.

JANIK, Ch. V.: Die Linzer Lößprofile in pedologischer und epirogen-tektonischer Sicht. - Naturkundl. Jb. der Stadt Linz, 235-255, Linz 1969.

JARIAZ, G.: Untersuchungen an fossilen Tertiärböden und vulkanogenen Edaphoiden des Westerwaldes. - Diss., Bonn 1966.

KLíma, B.: Ubersicht über die jüngsten paläolithischen Forschungen in Mähren. - Quartär (Jb. Erforsch. Eiszeit.), 9, 85-130, 1957.

KLINGE, H.: Uber spanische Terra rossa-Vorkommen und die Möglichkeiten ihrer zeitlichen Einordnung auf Grund bodengeographischer Studien. - Z. Pfl.Ernähr. Düng., 76, 3, 223-231, 1957.

- : Eine Stellungnahme zur Altersfrage von Terra-rossa-Vorkommen (unter besonderer Berücksichtigung der Iberischen Halbinsel, der Balearischen Inseln und Marokkos). - Z. Pfl.Ernähr., Düng., 81, 2, 56-63, 1958.

KretzoI, M.: Die altpleistozänen Wirbeltierfaunen des Villányer Gebirges. - Geol. hung. (Ser. palaeont.), 27, Budapest 1956.

Kriger, N. I.: Löss kak produkt geografičeskoj sredy. - Trudy Komm. po Iz. četv. Perioda, 19, 117-139, Moskva 1962.

KubiËNA, W. L.: Bestimmungsbuch und Systematik der Böden Europas. - Stuttgart 1953.

- : Zur Mikromorphologie, Systematik und Entwicklung der rezenten und fossilen Lößböden. Eiszeitalter u. Gegenwart, 7, 102-112, Öhringen 1956 (1956a).

- : Zur Methodik der Paläopedologie. - Actes du IV Congrès Internat. du Quaternaire (RomePise, Août-Septembre 1953), 297-305. - Roma 1956 (1956b).

- : Zur Mikromorphologie und Mikromorphogenese der Lößböden Neuseelands. - Soil Micromorphology (ed. by A. Jongerius), 219-235, Amsterdam 1964.

Kukla, J.: Quaternary Sedimentation Cycle. - Survey of Cyechoslovak Quaternary. - Instytut Geol., Prace, 34, 145-154, Warszawa 1961 (1961a).

- : Lithologische Leithorizonte der tschechoslowakischen Lößprofile. - Věst. ústřr. Úst. geol., 36, 369-372, Prag 1961 (1961b).

KukLA, J. \& LožEK, V.: Loesses and Related Deposits. - Survey of Czechoslovak Quaternary. Instytut Geol., Prace, 34,11-28, Warszawa 1961.

- : Význam krasových oblastí pro poznání poledové doby. (The Role of Karst in the Investigation of the Postglazial). - Čsl. Kras 1970 (im Druck).

Kukla, J., Ložek, V. \& Bárta, J.: Das Lößprofil von Nové Mesto im Waagtal. - Eiszeitalter u. Gegenwart, 13, 1-29, OOhringen 1962.

Lautridau, J. P.: Commission de terminologie des limons. - Mémoire hors série, Soc. Géol. de France, 5, 123-137, Paris 1969.

Liu Tung-sheng - Chang Tsung-hu: The „Huangtu“ (Loess) of China. - Report of the VIth Internat. Congress on Quaternary, Warsaw 1961, Vol. IV (Symposium on Loess), 503-524, Lódž 1964.

LožEK, V.: Měkkýši šeskoslovenského kvartéru. - (Mollusken des Tschechoslowakischen Quartärs). - Rozpr. ústř̀. Úst. geol., 17, Prag 1955.

- : Quartärmollusken der Tschechoslowakei. - Rozpr. ústř. Úst. geol., 31, Prag 1964 (1964a).

- : Stratigraphische Bedeutung der Quartärmollusken. - Report of the VIth Internat. Congress on Quaternary, Warsaw 1961, Vol. IV, Symposium on Loess, 525-549, Lódž 1964 (1964b).

- : Die quartäre Klimaentwicklung in der Tschechoslowakei. - Quartär (Quartär Jb. Erforsch. Eiszeit.), 17, 1-19, 1966.

- : Über die malakozoologische Charakteristik der pleistozänen Warmzeiten mit besonderer Berücksichtigung des letzten Interglazials. - Ber. deutsch. Ges. geol. Wiss., A, Geol.-Paläont., 14, 4, 439-469, 1969.

LožEK, V. \& KukLA, J.: Das Lößprofil von Leitmeritz an der Elbe, Nordböhmen. - Eiszeitalter u. Gegenwart, 10, 81-104, Ơhringen 1959.

LožEK, V. \& Skřivánek, F.: The Significance of Fissures and their Fills for Dating of Karst Processes. - Čs. Kras, 17, 7-22, 1966.

LožEK, V. \& TYráčEK, J.: Př́íspěvek k poznání vývoje údulí Váhu mezi Trenčínem a Pieštany. Sbor. čsl. Spol. zeměpis., 55, 6-14, 1960.

LuKAŠEv, K. I.: Problem lëssov v svete sovremennych predstavlenij. - Izdatělstvo AN BSSR, Minsk 1961.

Macoun, J.: Stratigrafie sprašových pokryvů na Opavsku. - Př́rodověd. Čas. slezský, 23, 15-24, Opava 1962.

Meusel, H.: Vergleichende Arealkunde, I. - (Verl. Bornträger), Berlin 1943.

MusıL, R.: Geologická situace na paleolitickém nalezišti v Rozdrojovicích u Brna. - Čas. morav. Mus. Brno, 15, 5-37, 1955. 
Mückenhausen, E.: Entstehung, Eigenschaften und Systematik der Böden der Bundesrepublik Deutschland. - DLG-Verlag, Frankfurt am Main, 1962.

PeLíšEK, J.: Př́spěvek ke stratigrafii spraší svrateckého úvalu (A contribution to the stratigraphie of loess in the Svratka river valley [Czechoslovakia]). - Práce Mor.-slez. Akad. Věd přír., 21, 11, Brno 1949.

—: Pleistocenní sprašové zeminy a holocenní říční sedimenty karpatské oblasti východního Slovenska (Pleistozäne Lößlehme und holozäne Fluß-Sedimente im Karpatengebiet der Ostalowakei, ČSSR). - Antropozoikum, 9, 175-201, Prag 1961.

Picard, K.: Zur Untergliederung der Saalevereisung im Westen Schleswig-Holsteins. - Z. d. dtsch. geol. Ges., 62, 2, 316-325, 1960.

Richmond, G. M. \& Frye, J. C.: Stratigraphic Commission, Note 19 - Status of Soils in Stratigraphic Nomenclature. - Bull. of the American Assotiation of Petroleum Geologists, 41, 4, 758-763, 1957.

RohdenburG, H.: Ein Beitrag zur Deutung des „Gefleckten Horizontes“. - Eiszeitalter u. Gegenwart, 15, 66-71, Öhringen 1964.

Ruske, R. \& WÜNsche, M.: Lösse und fossile Böden im mittleren Saale- und unteren Unstruttal. Geologie, 10, 9-29, 1961.

Schönhals, E.: Über fossile Böden im nichtvereisten Gebiet. - Eiszeitalter u. Gegenwart, 1, 109-130, Ơhringen 1951 (1951a).

- : Fossile gleiartige Böden des Pleistozäns im Usinger Becken und am Rand des Vogelberges. Notizblatt hess. Landesamtes f. Bodenforschung Wiesbaden, 6, 160-183, 1951 (1951b).

Schönhals, E., Rohdenburg, H. \& SEMmel, A.: Ergebnisse neuerer Untersuchungen zur WürmlößGliederung in Hessen. - Eiszeitalter u. Gegenwart, 15, 199-206, Öhringen 1964.

Schroeder, D.: Mineralogische Untersuchungen an Lößprofilen. - Heidelb. Beitr. z. Min. u. Petrogr., 4, 6, 45-65, 1955.

SmoLíkoví, L.: Fosilní skvrnité půdy v ČSSR (Předběžná zpráva). (Fossle gefleckte Böden in der Tschechoslowakei). - Věst. ústřr. Úst. geol., 35, 371-373, Prag 1960.

- : Stratigraphical significance of Terrae Calcis soils. - INQUA, Abstracts of Papers, PWN, 34-35, Lódź 1961.

— : Půdy typu lessivé (parahnědozemě) v okolí Letovic. (Die Lessivé-Böden in der Umgebung von Letovice [Mähren]). — Čas. Mineral. Geol., 7, 316-321, 1962.

- : Stratigraphische Bedeutung der Terrae calcis-Böden. - Antropozoikum, Sbor. geol. Věd, A, 1, 101-126, Prag 1963 (1963a).

- : Ráz výskytu terrae calcis v krasových oblastech Slovenska. (Different Forms of Occurence of Terrae Calcis in Karst Areas of Slovakia). - Čs. Kras, 14, 93-100, 1963 (1963b).

- : Výzkum kvartéru na listech B. Bystrica a Sl.'Lúpča. (Listy M-34-111-C a M-34-111-D). Zpr. geol. Výzk., 276-277, 1964.

— : Mikromorphologie der altpleistozänen Fossilböden von Červený kopec bei Brno (Brünn). (Vorläufige Mitteilung). - Věst. ústř. Úst. geol., 42, 369-373, Prag 1967.

- : Polygenese der fossilen Lößböden der Tschechoslowakei im Lichte mikromorphologischer Untersuchungen. - Geoderma, 1, 315-324, Amsterdam 1968 (1968a).

- : Genese mladopleistocenních půd v Modřicích u Brna na základè půdní mikromorfologlie. (Genese der jungpleistozänen Fossilböden von Modřice bei Brno auf Grund mikromorphologischer Untersuchungen). - Čas. Mineral. Geol., 13, 199-209, 1968 (1968b).

— : Bedeutung der Paläoböden im Rahmen des quartären klimatischen Zyklus. - Antropozoikum, Prag 1972 (im Druck).

Smolíkova, L. \& LožEK, V.: Zur Altersfrage der mitteleuropäischen Terrae calcis. - Eiszeitalter u. Gegenwart, 13, 157-177, Óhringen 1962.

- : The Holocene Soil Complex of Litoměřice. - Antropozoikum, Sbor. geol. Věd, A, 2, 41-56, Prag 1964.

- : Stratigrafičeskoe i paleoklimatičeskoe značenie četvertičnych iskopaemych počv Srednej Evropy. - Bjulletin Komm. po Iz. četv. Perioda, 33, 30, 26-46. - AN SSSR, Moskva 1965.

Werner, J.: Gips-Ausblühungen an Bodenaufschlußwänden. - Pfl.Ernähr. Düng., 47, 3-9, Weinheim 1960.

ZaChARIAE, G.: Der Einsatz mikromorphologischer Methoden bei bodenzoologischen Arbeiten. Geoderma, 1, 175-195, Amsterdam 1967.

ZagwiJn, W. \& PAEPE, R.: Die Stratigraphie der weichselzeitlichen Ablagerungen der Niederlande und Belgiens. - Eiszeitalter u. Gegenwart, 19, 129-146, OOhringen 1968.

Záruba, Q., LožEK, V. \& KuKLA, J.: Starokvartérní sedimenty v hliništi cihelny u Žalova. (Die altquartären Ablagerungen in der Ziegelei von Žalov bei Prag). - Věst. ústř. Úst. geol., 35, 225-228, Prag 1960. 
ŽEBERA, K.: K současnému výzkumu kvartéru v oblasti Českého masivu. (A propos de l'exploration actuelle des terrains .uaternaires dans le domaine du Massif Bohémien). - Sbor. St. geol. Úst., 16, 731-781, 1949.

Manuskr. eingeg. 16. 1. 1970.

Anschrift der Verfasserin: Doz. Dr. Libuše Smolíková, Lehrkanzel der Geologie der Karls-Universität, Prag II, Albertov 6. 